\title{
'GolfStar', a Turf, Ornamental, and Reclamation Cultivar of North American Native Idaho Bentgrass
}

\author{
A. Douglas Brede ${ }^{1}$ \\ Research Department, J.R. Simplot Company, Jacklin Seed, W5300 Riverbend \\ Avenue, Post Falls, ID 83854
}

Additional index words. turfgrass breeding, native grasses, ornamental grass, black bent

'GolfStar' Idaho bentgrass (Agrostis idahoensis Nash.) is a novel cultivar released in Sept. 1999 by the J.R. Simplot Company. 'GolfStar' is the first recognized cultivar of this fine-bladed Rocky Mountain bentgrass species, indigenous from New Mexico to Alaska (Hitchcock, 1951). Idaho bentgrass is distinct from the introduced exotic species of creeping (A. stolonifera L.) and colonial (A. tenuis Sibth.) bentgrass, and most closely resembles dryland bentgrass (A. castellana Boiss. \& Reuter). Idaho bentgrass has 28 chromosomes and can be distinguished by its seed and flowering characteristics, and its lack of rhizomes and stolons. 'GolfStar' averages $10,650 \mathrm{seeds} / \mathrm{g}$, intermediate between redtop (A. gigantea Roth) and creeping bentgrass, and its seed characteristically lacks a palea. Plants of 'GolfStar' flower in mid-July (in Idaho) at a height of $0.5 \mathrm{~m}$, with a brilliant purplish-red color.

\section{Origin}

'GolfStar' was bred from plants collected in the Coeur d'Alene river basin in northern Idaho from 1988 through 1990. Plants were selected from native stands downstream from an Environmental Protection Agency (EPA) Super Fund site (EPA, 2002). The collection area was contaminated with heavy metals from years of deep-rock mining. Seeds from hundreds of accessions were brought back to our Post Falls site and grown in a 15,000-plant selection nursery. Only a small fraction of the collected plants initially demonstrated turf potential. In general, the performance of wild-type A. idahoensis plants in turf was similar to that of common redtop. However, turf quality improved to acceptable levels after two to three cycles of selection and intercrossing.

The breeding history of 'GolfStar' is complex, owing to the number of polycrosses that make up its background. 'GolfStar,' as a cultivar, was assembled in 1993, in a 0.5-ha spaced-plant breeder nursery near Albany, Ore. The nursery had four replicates of alternating 100-plant rows of six breeding lines: 92-1549, 92-1543, 92-1231, 92-1163, 92-1097, and 921165 . The field was planted from plugs grown from shoots extracted from a 1992 turf trial.

Received for publication 30 Sept. 2002. Accepted for publication 6 May 2003.

1E-mail address: dbrede@ jacklin.com
Plants uncharacteristic of the cultivar were rogued before anthesis in 1994, removing $20 \%$ of the population.

The best way to simplify the breeding history of 'GolfStar' is to examine each of its six parent lines:

92-1549 originated in 1989 as accession 89-0848, collected by boat from the shores of Killarney Lake, near Harrison, Idaho. A plant selected from a spaced planting of 89-0848 progeny was used as one of nine clones in polycross 90-8010, which was grouped for fine texture, low density, dark color, and medium maturity. Seed from the $89-0848$ plant was designated 90-0606, and was evaluated in a 1991 turf trial. A selection from 90-0606 was later entered as one of nine plants in 1992 polycross 92-8004, grouped based on the Poa-like characteristics of the spaced plants, and a moderately upright growth habit. Seed 92-1549.

92-1543 also originated as a progeny of 89-0848 and was entered in polycross $90-8010$ (described above). In 1992, a clone selected from the progeny of 89-0848 was entered into polycross $92-8002$, which consisted of 10 plants grouped together for fine leaf texture, from the 90-0606 plant line was designated

early maturity, and prostrate seedheads. The resulting seed was designated 92-1543.

92-1231 also traces to 89-0848. A selected clone from 89-0848 was designated 90-0651 and was entered as one of 28 clones in polycross 90-8012, based on fine texture, good shoot density, and late maturity. In 1992, a selection from 90-0651 was entered into polycross 928004 (described above). The resulting seed from 90-0651 was designated 92-1231.

92-1163 also traces to 89-0848, a selected clone of which was entered into 1992 polycross 92-8005. This polycross of six plants was grouped on early reproductive maturity and a moderately upright growth habit. The seed from this clone was designated 92-1163.

92-1097 originated in 1989 as accession 89-0945, collected near the Schlepp farm near Rose Lake, Idaho (Fig. 1). A plant selected from 89-0945 was designated 90-0638 and was used as one of 23 clones in polycross 90 8013, which was grouped for very fine texture, prostrate seedheads, and early maturity. Seed from 90-0638 was evaluated in a 1991 turf trial. A selection from $90-0638$ was entered into polycross $92-8002$ (described above) in 1992. Seed from this clone was designated 92-1097.

92-1165 originated from accession 890963, which was found in 1989 growing near the same location as accession 89-0945. Aplant selected from 89-0963 was used as one of 28 clones in polycross 90-8012 (described above). Seed from that clone was designated 90-0641 and was tested in a 1991 turf trial. A selection from 90-0641 was entered into polycross 928002 (described above) in 1992. Seed from that clone was designated 92-1165.

\section{Description}

In northern Idaho, flowering of 'GolfStar' occurs in mid- to late July, and swathing time is usually around 1 Aug. (Table 1). At anthesis,

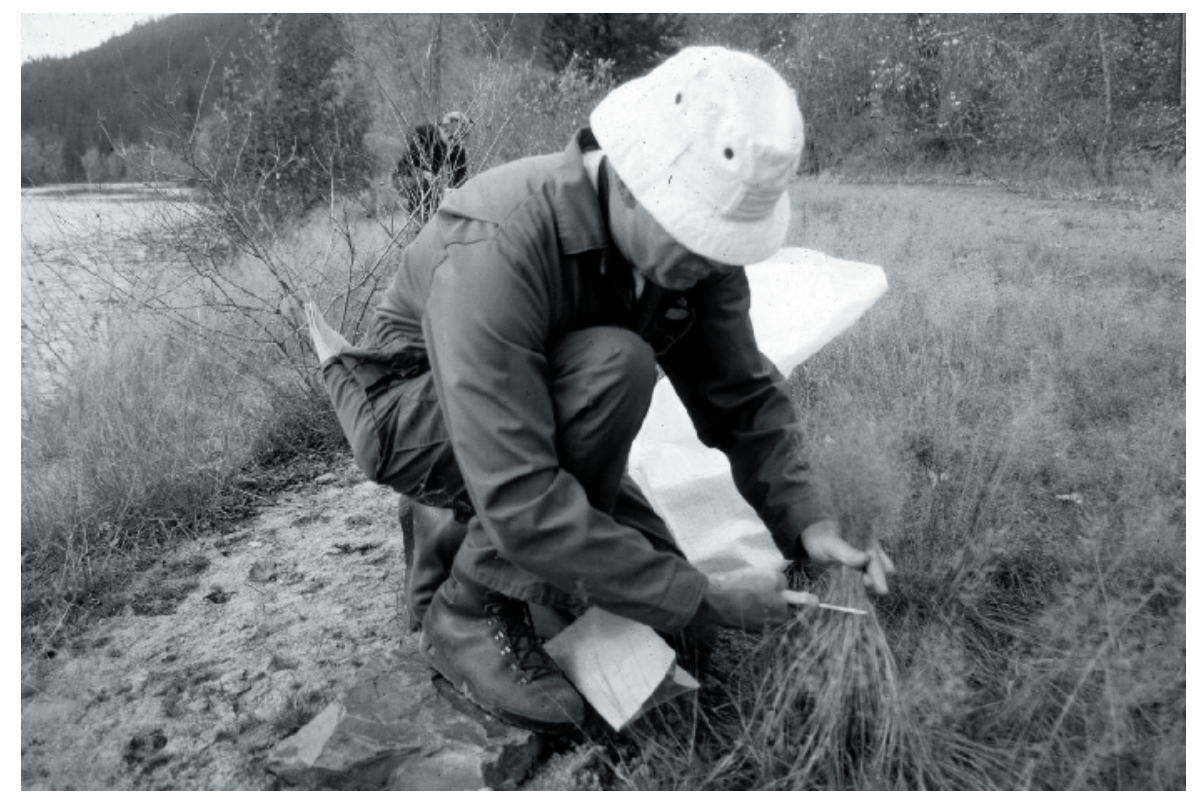

Fig. 1. Collecting native plants of Idaho bentgrass along the sandy banks of the Coeur D'Alene River in 1989 , in an area receiving $500 \mathrm{~mm}$ of annual precipitation 
the cultivar has a brilliant purplish-red panicle color. By swathing time, heads turn a rusty tan color, while the underlying foliage remains mostly vibrant green. Idaho bentgrass is noted for its drought tolerance and persistence under low precipitation (Cronquist et al., 1977; Hitchcock, 1951).

During its breeding, 'GolfStar' was optimized for a $3-\mathrm{cm}$ mowing height (Fig. 2). Therefore, 'GolfStar' is best suited for lawns, parks, golf courses, roadsides, and sports turf where the mowing height is above $2 \mathrm{~cm}$. It lacks lateral stems and does not exhibit the false crowns at higher mowing heights associated with the exotic bentgrass species (Fig. 3). Idaho bentgrass is noteworthy for its tolerance to damp shade. The cultivar may possess tolerance to heavy metal contamination (owing to its origins), but this assertion has not been empirically verified. 'GolfStar' was entered into the 1998 National Turfgrass Evaluation Program (NTEP) fairway/tee trial (Morris, 2002), where its performance was similar to that of colonial bentgrass, but with a generally darker leaf color. 'GolfStar' was the top-scoring entry in overall quality in the NTEP trial site in South Dakota. Bonos et al. (1998) found 'GolfStar' to be less susceptible to dollar spot (Sclerotinia homoeocarpa F.T. Bennett) than other Agrostis, and Brede (1999) found it to be equal in brown patch (Rhizoctonia solani Kuhn) resistance to leading perennial ryegrass (Lolium perenne L.) and tall fescue (Festuca arundinacea Schreb.) cultivars. 'GolfStar' is compatible in mixtures with fine fescue (Festuca sp.), providing an attractive "links" appearance, even at higher mowing heights. It has also been successfully tested for winter overseeding of bermudagrass putting greens, where it exhibited rapid germination and early spring transition, similar to Poa trivialis L. (Anderson and Dudeck, 1995; Kopec and Gilbert, 1995).

\section{Availability}

Seed is produced and breeder seed is maintained by Simplot. Seed propagation is limited to four cycles of increase: Breeder, Foundation, Registered, and Certified. 'GolfStar' Idaho bentgrass and all germplasm derived from it are protected under U.S. utility patent $5,981,853$. The experimental designation for 'GolfStar' was J-100.

\section{Literature Cited}

Anderson, S.F. and A.E. Dudeck. 1995, 1994-95 Overseeding trials in North Florida. Univ. of Florida, Gainesville.

Bonos, S.A., J. Murphy, W.A. Meyer, B.B. Clarke, K.A. Plumley, W.K. Dickson, J.B. Clark, J.A Honig, and D.A. Smith. 1998. Performance of bentgrass cultivars and selections in New Jersey turf trials. 1998 Rutgers Turfgrass Proc. 30:33-38.

Brede, A.D. 1999. Idaho bentgrass: A new species

Table 1. Plant height, panicle length, and flag leaf length of 'GolfStar' Idaho bentgrass in Post Falls, Idaho. The uniformity of culm length is fairly consistent, although culms tend to be longer at the center of clonal plants and shorter toward the periphery.

\begin{tabular}{llcc}
\hline Characteristic & \multicolumn{1}{c}{ Length measured from: } & $\begin{array}{c}\text { Mean } \\
(\mathrm{cm})\end{array}$ & $\begin{array}{c}\text { 95\% Confidence } \\
\text { interval }(\mathrm{cm})\end{array}$ \\
\hline Culm & Basal crown to tip of panicle & 54 & 50.8 to 57.7 \\
Panicle & Lowest node to panicle tip & 10 & 8.2 to 11.7 \\
Flag leaf & Sheath collar to blade tip & 3.8 & 2.8 to 4.6 \\
\hline
\end{tabular}

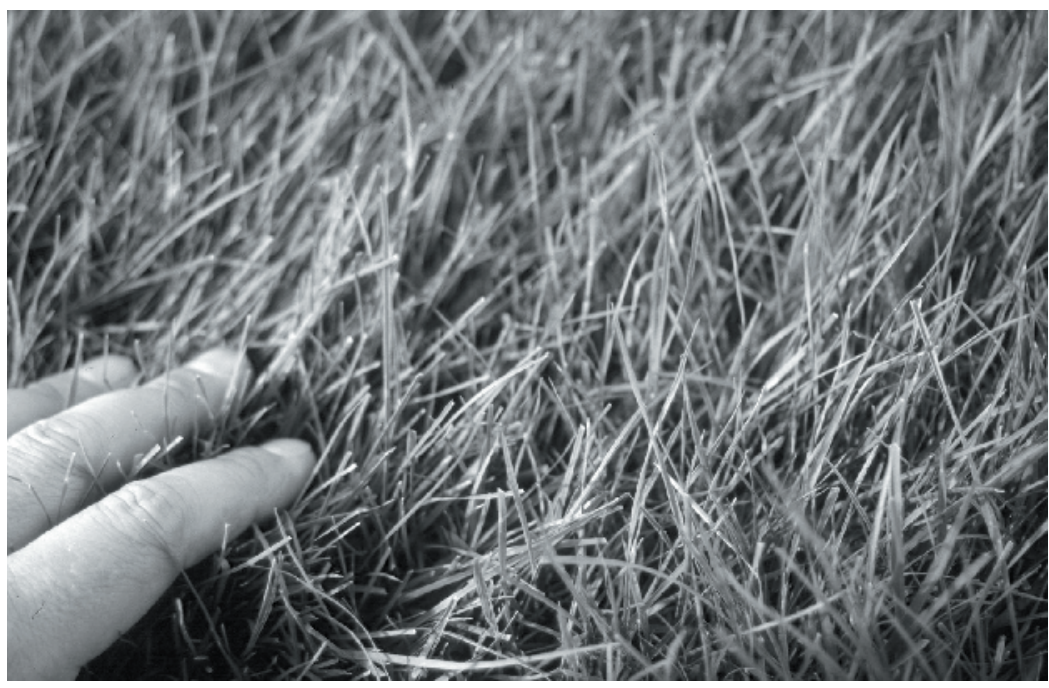

Fig. 2. Fine-textured turf produced by 'GolfStar' Idaho bentgrass in Maryland test plots mowed at $5 \mathrm{~cm}$. Other bentgrass species produce false crowns at this mowing height, giving a stemmy, scalped appearance.

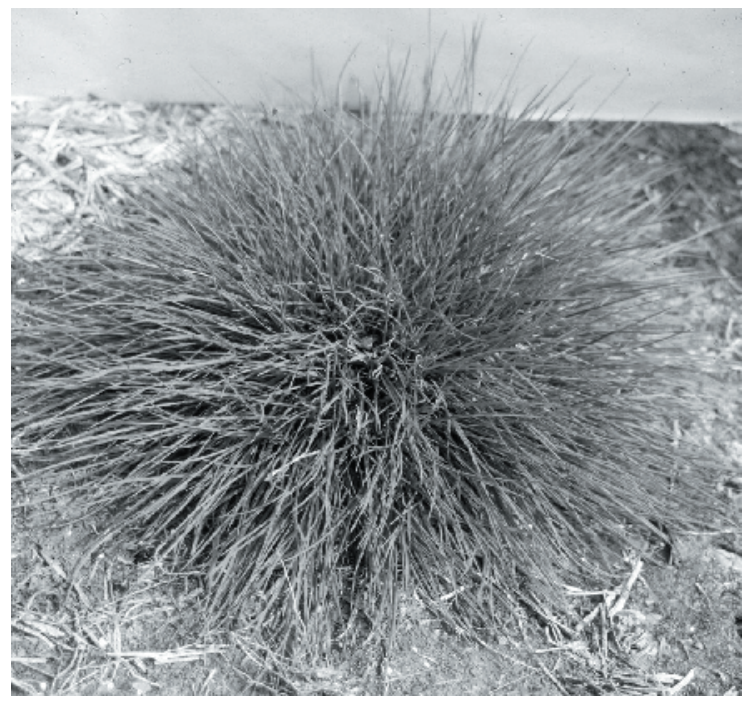

Fig. 3. A clonal spaced plant of 'GolfStar' Idaho bentgrass, showing its bunch-type habit, similar to perennial ryegrass (Lolium perenne L.). Photo was taken in late June just prior to heading.

for turf. Agron. Abstr. Vol. 91, p. 134

Cronquist, A., A.H. Holmgren, N.H. Holmgren, J.L. Reveal, and P.K. Holmgren. 1977. Intermountain flora. Columbia Univ. Press, New York.

Environmental Protection Agency. 2002. Bunker Hill-Coeur d'Alene river basin. http: //yosemite.epa.gov/r10/cleanup.nsf/sites/cda (verified 21 Apr. 2003).
Hitchcock, A.S. 1951. Manual of the grasses of the United States. USDA Misc. Publ. 200.

Kopec, D.M. and J.J. Gilbert. 1995. Overseed greens performance trial 1994-1995. Univ. of Arizona, Tucson.

Morris, K.N. 2002. Fairway/tee bentgrass test 1998. Prog. Rpt. NTEPNo. 02-3, Natl. Turfgrass Evaluation Program, USDA-ARS, Beltsville, Md. 